\title{
Cyclic deformation behaviour and stability of grain-refined 301LN austenitic stainless structure
}

\author{
Jiř́ Man ${ }^{1, *}$, Antti Järvenpää ${ }^{2}$, Matias Jaskari ${ }^{2}$, Ivo Kuběna ${ }^{1}$, Stanislava Fintová ${ }^{1}$, Alice Chlupová ${ }^{1}$, L. Pentti Karjalainen ${ }^{3}$, \\ and Jaroslav Polák ${ }^{1}$ \\ ${ }^{1}$ Institute of Physics of Materials ASCR, Žižkova 22, 61662 Brno, Czech Republic \\ ${ }^{2}$ Kerttu Saalasti Institute, University of Oulu, Pajatie 5, 85500 Nivala, Finland \\ ${ }^{3}$ Centre for Advanced Steels Research, University of Oulu, P.O. Box 4200, 90014 Oulu, Finland
}

\begin{abstract}
Low cycle fatigue (LCF) behaviour of metastable austenitic $301 \mathrm{LN}$ stainless steel with different grain sizes - coarse-grained $(13 \mu \mathrm{m})$, fine-grained $(1.4 \mu \mathrm{m})$ and ultrafine-grained $(0.6 \mu \mathrm{m})$ - produced by reversion annealing after prior cold rolling was investigated. Fully symmetrical LCF tests with constant total strain amplitudes of $0.5 \%$ and $0.6 \%$ were performed at room temperature with a low constant strain rate of $2 \times 10^{-3} \mathrm{~s}^{-1}$. Microstructural changes in different positions within the gauge part of the specimens were examined by optical microscopy (polarized light) and electron backscatter diffraction (EBSD) technique; for quantitative assessment of the volume fraction of deformation induced martensite (DIM) a Feritscope FMP 30 was adopted. The cyclic stress-strain response and specific changes of hysteresis loop shapes in the very early stage of cycling are confronted with the character of DIM formation and its distribution in the whole volume of the material. A possible effect of strain rate (frequency of cycling) on the destabilization of austenitic structure during cyclic straining of materials with different grain sizes is highlighted.
\end{abstract}

\section{Introduction}

Grain refinement of metastable austenitic steels via so called reversion annealing after prior cold deformation attracts deserved interest of researches for many decades since it represents an effective tool for considerable improvement of tensile properties [1]. The choice of proper parameters of this thermomechanical treatment, namely the level of cold deformation and temperature and time of reversion annealing can lead up to ultrafinegrained (UFG) microstructure with an excellent combination of high strength and good ductility - see e.g. [2-12].

Whereas the behaviour of grain-refined austenitic steels during unidirectional tensile testing has been intensively studied (see above), to the behaviour of these materials during cyclic straining has been paid much less attention so far [10,13-17]. Very limited number of papers [13,15-17] indicates positive effect of grain refinement on the fatigue life of austenitic steels cycled under low-cycle fatigue (LCF) conditions.

Järvenpää et al. [10] recently studied LCF behaviour and structure destabilization of $301 \mathrm{LN}$ steel reversionannealed to different grain sizes ranging from $13 \mu \mathrm{m}$ to $0.6 \mu \mathrm{m}$ and cyclically strained with constant total strain amplitudes of $0.4 \%$ and $0.6 \%$. They reported that the most stable structure during fatiguing with relatively high frequencies of $6 \mathrm{~Hz}$ and $1 \mathrm{~Hz}$, was unexpectedly at both strain amplitudes the fine-grained structure with average grain size of $1.4 \mu \mathrm{m}$. The kinetics of deformation induced martensite (DIM) formation was found to deviate systematically from the other stainless steels [10].

The present work represents a continuation of our previous studies on the cyclic plasticity, stress-strain response and microstructural changes in grain refined 301LN steel cyclically strained under LCF conditions. To bring some new insight into the above unexpected behaviour strain controlled test with constant low strain rate of $2 \times 10^{-3} \mathrm{~s}^{-1}$ was adopted. The cyclic stress-strain response and characteristic changes of hysteresis loop shape of $301 \mathrm{LN}$ steel with various grain sizes are confronted with microstructural changes documented in different locations of a sheet material both in situ during cycling and after interruption of cycling at the very early stage of fatigue life.

\section{Experimental}

A commercial austenitic $301 \mathrm{LN}$ stainless steel with the chemical composition (in wt.\%) $0.025 \mathrm{C}, 0.53 \mathrm{Si}$, $1.25 \mathrm{Mn}, 0.024 \mathrm{P}, 0.001 \mathrm{~S}, 17.5 \mathrm{Cr}, 6.5 \mathrm{Ni}, 0.2 \mathrm{Cu}, 0.09 \mathrm{Mo}$, $0.15 \mathrm{~N}$, and rest Fe was supplied by Outokumpu Stainless Oy (Tornio, Finland) in the form of $8 \mathrm{~mm}$ thick, hot rolled and annealed sheet. The sheet was subjected to the following thermo-mechanical treatment at the University of Oulu, Finland. Sheet material with initial fully austenitic structure was cold rolled (CR) with the 
Table 1. Conditions of RA, average grain size and tensile characteristics of various microstructural states of 301LN steel [10].

\begin{tabular}{|c|c|c|c|c|c|c|}
\hline \multirow{2}{*}{$\begin{array}{l}\text { Microstructural } \\
\text { state }\end{array}$} & \multicolumn{2}{|c|}{ Reversion annealing conditions } & \multirow{2}{*}{$\begin{array}{l}\text { Average grain } \\
\text { size }\end{array}$} & \multicolumn{3}{|c|}{ Tensile characteristics* } \\
\hline & Temperature & Holding time & & $\mathbf{Y S}$ & UTS & $\varepsilon_{\mathrm{f}}$ \\
\hline CGA1 & $1050^{\circ} \mathrm{C}$ & $200 \mathrm{~s}$ & $13 \mu \mathrm{m}$ & $340 \mathrm{MPa}$ & $960 \mathrm{MPa}$ & $72 \%$ \\
\hline FGA & $900^{\circ} \mathrm{C}$ & $1 \mathrm{~s}$ & $1.4 \mu \mathrm{m}$ & $550 \mathrm{MPa}$ & $1025 \mathrm{MPa}$ & $67 \%$ \\
\hline UFGA & $800^{\circ} \mathrm{C}$ & $1 \mathrm{~s}$ & $0.6 \mu \mathrm{m}$ & $750 \mathrm{MPa}$ & $1100 \mathrm{MPa}$ & $57 \%$ \\
\hline
\end{tabular}

* YS $=$ yield stress, UTS $=$ ultimate tensile strength, $\varepsilon_{\mathrm{f}}=$ strain to fracture

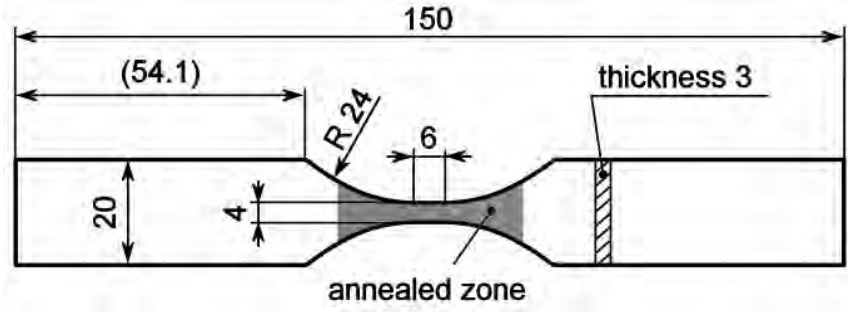

(a)

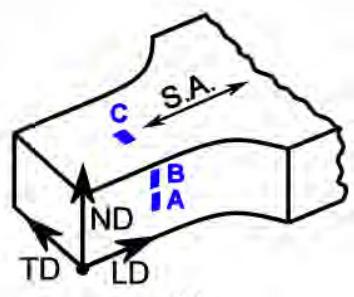

(b)

Fig. 1. Schema of specimen geometry (a) and specimen gauge part (b) with indicated positions of microstructural observations. All dimensions are in $\mathrm{mm}$.
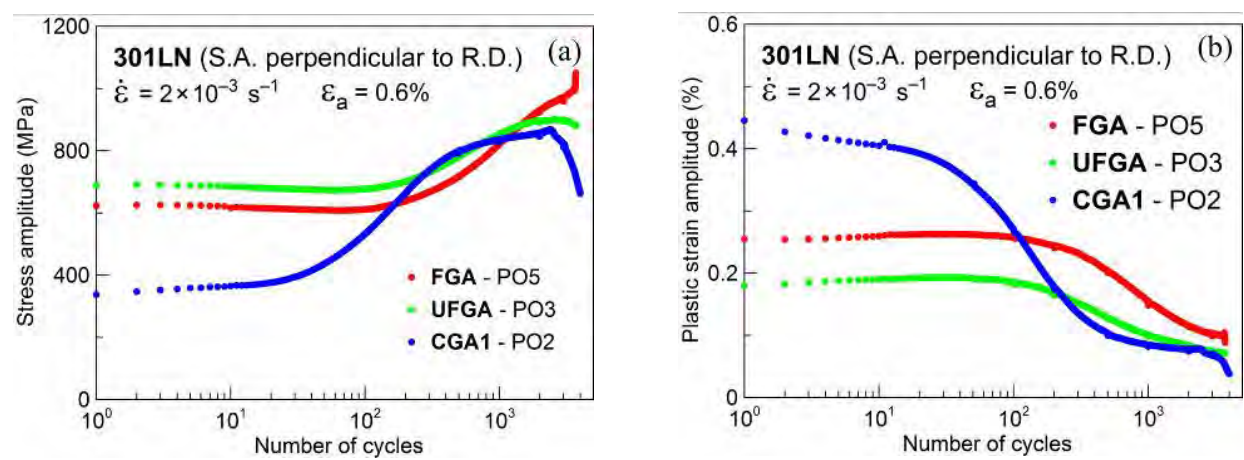

Fig. 2. Stress amplitude (a) and plastic strain amplitude (b) versus number of cycles in 301LN steel with three different grain sizes.

reduction of $63 \%$ to the thickness of $3 \mathrm{~mm}$. Rectangular pieces $20 \times 150 \mathrm{~mm}$ were cut from the CR sheet both perpendicular and parallel to the rolling direction. The pieces were reversion annealed with a high heating rate of $200{ }^{\circ} \mathrm{C} / \mathrm{s}$ and cooling rate of $35^{\circ} \mathrm{C} / \mathrm{s}$ on a Gleeble 3800 thermo-mechanical simulator. The adoption of three different annealing conditions resulted in fully austenitic microstructures with different grain sizes, namely the coarse-grained (CGA1), fine-grained (FGA) and ultrafine-grained (UFGA) - see Table 1 where the basic tensile characteristics are also listed. More details on the thermomechanical treatment, characterization of microstructure including its behaviour during tensile tests can be found elsewhere $[9,10]$.

From the processed $3 \mathrm{~mm}$ thick sheets of individual materials the flat dog-bone shaped specimens having the gauge width and length of $4 \mathrm{~mm}$ and $6 \mathrm{~mm}$, respectively, were machined by spark-erosion (see Fig. 1a). This geometry enabled to avoid the adoption of anti-buckling device used in our previous LCF tests $[15,16]$ which made possible to perform in situ Feritscope monitoring of $\alpha^{\prime}$-martensite formation on two perpendicular surfaces (positions $\mathrm{A}$ and $\mathrm{C}$ indicated in Fig. 1b). Before fatigue tests the central part of specimens was carefully polished mechanically and electrolytically.

LCF tests were conducted at room temperature in air in symmetrical push-pull cycle $(\mathrm{R} \varepsilon=-1)$ with constant total strain amplitudes of $0.5 \%$ and $0.6 \%$ to the different stages of fatigue life. Contrary to the recent study by Järvenpää el al. [10] the low strain rate of $2 \times 10^{-3} \mathrm{~s}^{-1}$ was kept constant during all fatigue tests. The volume fraction of magnetic phase ( $\alpha^{\prime}$-martensite) was assessed using a Feritscope Fischer MP30. The actual $\alpha^{\prime}$ martensite content was determined by multiplying the Feritscope reading by the correction factor of 1.7 [18]. During in situ measurements the measuring probe was attached to the specimen surface always after unloading from tension. After completion of fatigue tests the microstructural changes in different positions within the gauge part of specimens (see Fig. 1b) were examined by optical microscopy (polarized light and Beraha II colour etching) and EBSD (electron backscatter diffraction) technique in high-resolution SEM-FEG (LYRA 3 XMU from TESCAN) with a step size of $85 \mathrm{~nm}$.

\section{Results}

\subsection{Cyclic stress-strain response}

During cycling with constant total strain amplitude of $0.6 \%$ the stress and plastic strain amplitude were evaluated from the recorded hysteresis loops and they are plotted vs. number of cycles for all grain sizes (CGA1, FGA and UFGA) in Fig. 2. The cyclic hardening/softening curves are similar to those observed 

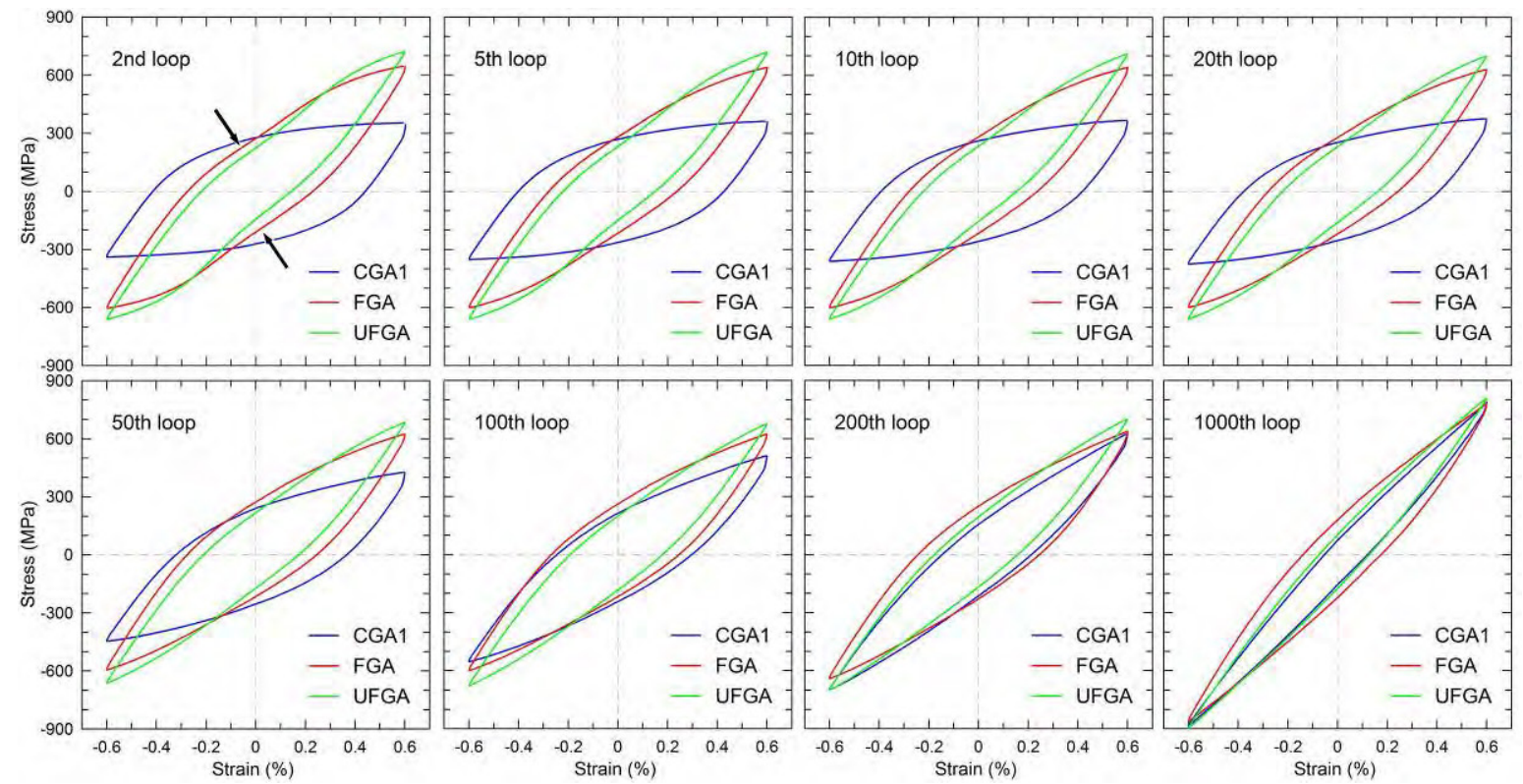

Fig. 3. Development of hysteresis loops in $301 \mathrm{LN}$ steel with different grain sizes during cyclic straining with $\varepsilon_{\mathrm{at}}=0.6 \%$.
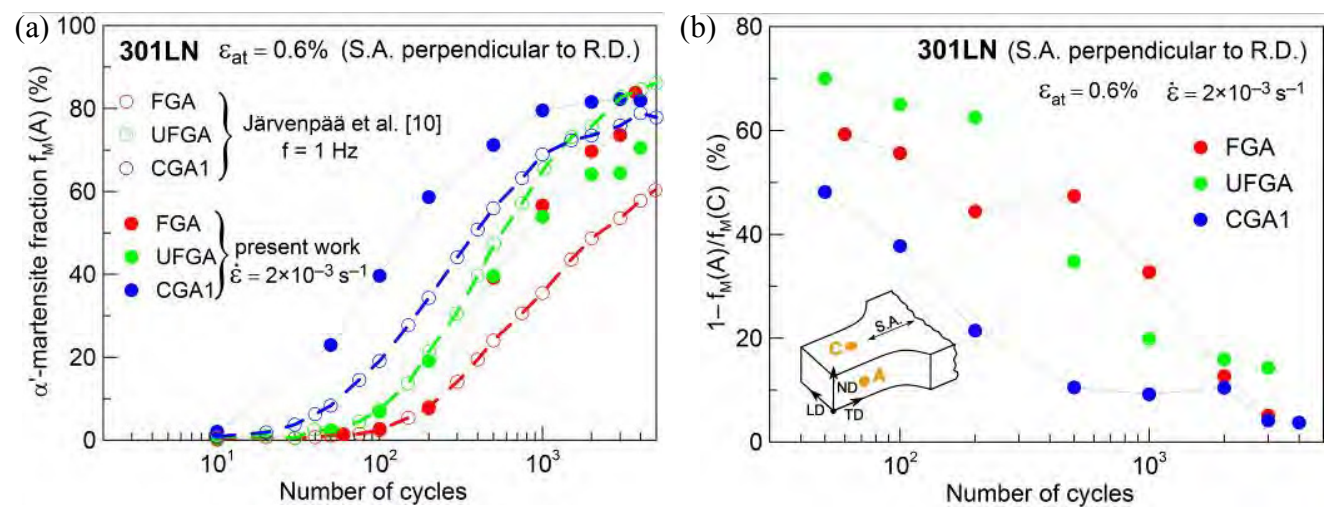

Fig. 4. Evolution of volume fraction of $\alpha^{\prime}$-martensite as assessed by Feritscope in position A (a) and relative difference in $\alpha^{\prime}-$ martensite fraction measured in positions A and C (b) in the sheet of various microstructures of 301LN steel cyclically strained with total strain amplitude of $0.6 \%$.

in our previous studies on the grain refined identical type $301 \mathrm{LN}$ austenitic stainless steel $[10,15,16]$. The stress amplitudes of FGA and UFGA steels at the start of cycling are considerably higher than that for coarsegrained counterpart (see Fig. 2a) which is in agreement with the differences in the yield stress (see Table 1).

The character of cyclic hardening/softening curves in $301 \mathrm{LN}$ steel of diverse grain sizes was different. Whereas only permanent hardening of different intensity during cycling was detected for CGA1 steel (cf. Figs. 2a and $2 \mathrm{~b})^{1}$ FGA and UFGA steels showed more complicated behavior. Contrary to their coarse-grained counterpart they exhibit the initial stage of mild

\footnotetext{
${ }^{1}$ The sudden drop in stress amplitude clearly visible for CGA1 steel after 2500 cycles resulted purely from the fatigue test layout due to Feritscope measurements on two perpendicular surfaces (see above) and did not reflect the true stress response of this steel. Since anti-buckling device was not adopted during fatigue tests the local bending of the specimens at the ends of specimen gauge length due to considerable hardening of the material during cycling became in later stages of fatigue life inevitable which resulted in virtual "cyclic softening".
}

softening which is after approximately 100 cycles superseded by a strong cyclic hardening. As will be shown below the increase of stress amplitude in all microstructural states can be correlated with their structural stability of austenite.

During fatigue tests the stress-strain response within a cycle, i.e. hysteresis loops were recorded. While the coarse-grained material exhibits the usual smooth shape of hysteresis loops during cycling, some irregularities in the form of loop constriction are apparent at the early stages of cycling for both UFGA and FGA materials. They are highlighted by black arrows in Fig. 3 for the second loops. In agreement with our previous results [15] hysteresis loops are constricted in the region of low applied stress for both tensile and compression part of a loop. With increasing number of elapsed cycles the constrictions becomes less pronounced and after approximately 150 cycles it disappears completely and the shape of hysteresis loop becomes normal (see Fig. 3). Similar hysteresis loop changes at the early stage of fatigue life were documented recently for UFGA and FGA steels also for much higher frequencies adopted during cyclic straining [19]. 

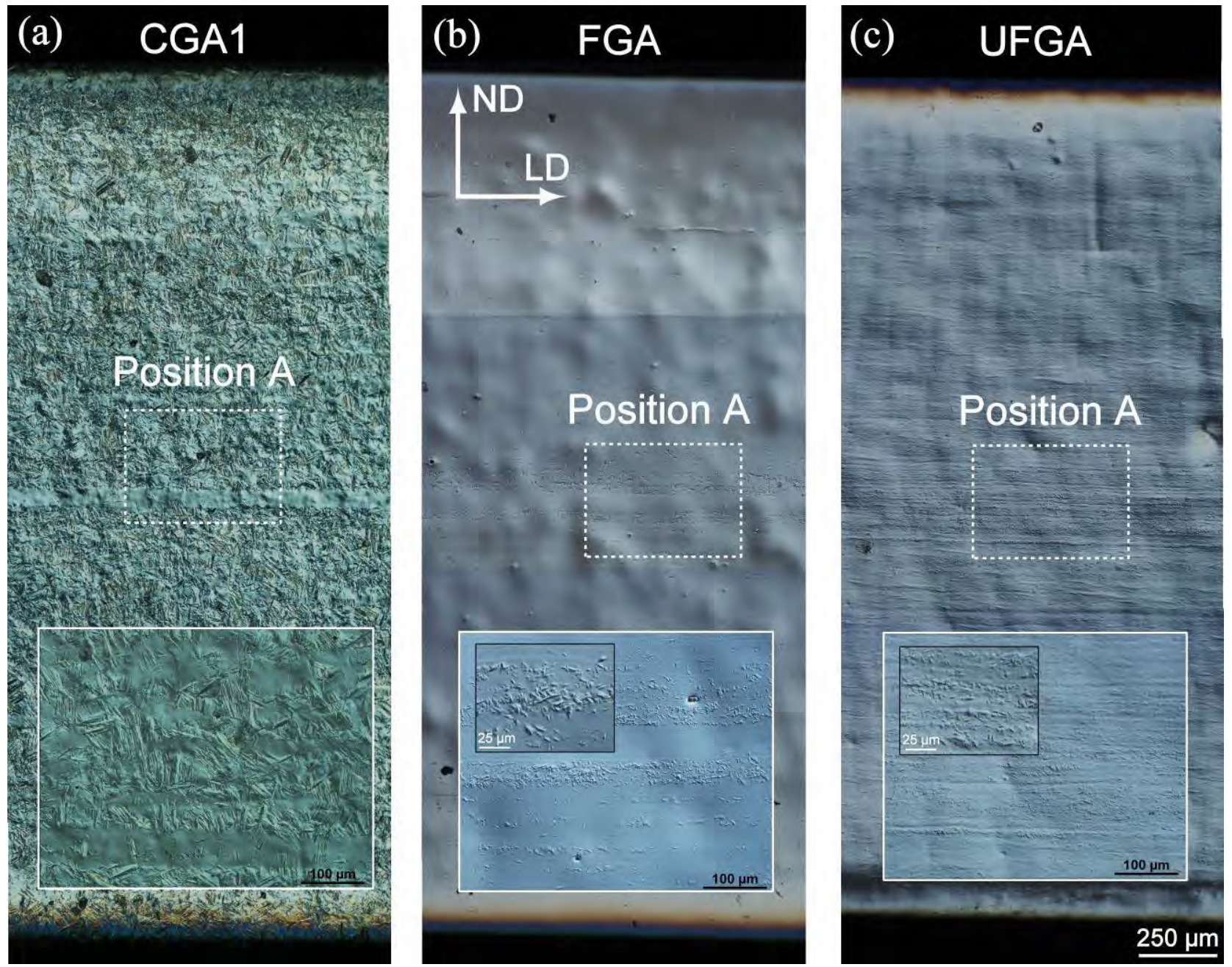

Fig. 5. Surface topography across the thickness of $301 \mathrm{LN}$ steel with different grain sizes fatigued with $\varepsilon_{\mathrm{at}}=0.5 \%$ to very early stage of fatigue life (OM, polarized light). Stress axis is horizontal in all micrographs (c.f. Fig. 1b).

\subsection{Deformation induced phase transformation}

\subsubsection{In situ monitoring of DIM formation during cyclic straining}

The results of present in situ Feritscope monitoring of destabilization of initially fully austenitic structure, i.e. magnetic $\alpha^{\prime}$-martensite formation in the course of cycling of all three materials are shown in Fig. 4a together with results obtained recently for identical materials for cycling with the same total strain amplitude but with much higher frequency of $1 \mathrm{~Hz}$ [10]. Note that in both studies specimens were fabricated perpendicular to the rolling direction and the $\alpha^{\prime}$-martensite content was assessed by the Feritscope probe attached in the position A, i.e. in the middle of sheet thickness (see the inset in Fig. $4 b)$.

As can be seen from Fig. 4a the kinetic curves of $\alpha^{\prime}$ martensite formation obtained in two laboratories (Oulu and Brno) exhibit similar, approximately sigmoidal shapes. In both laboratories the coarse-grained microstructure CGAl was found to be the most metastable structure in the early stage of cycling.
Irrespective of the small differences in the $\alpha^{\prime}$-martensite content in various microstructures during cycling which could be attributed, in addition to different applied strain rates, to larger cross-section area of the gauge part used by Järvepää et al. [10] a clear tendency to the similar $\alpha^{\prime}$ martensite content at the late stages of fatigue life is observed for all microstructures. The only exception represents the fine-grained structure cyclically strained with the frequency of $1 \mathrm{~Hz}$ which shows systematic deviation from the described behaviour and indicating thus higher stability of this microstructural state. However, as will be discussed later, for explanation of this discrepancy the actual temperature of the specimen gauge part and its increase during cycling should be also taken into account.

Another important result shows Fig. $4 \mathrm{~b}$ in which relative difference in $\alpha^{\prime}$-martensite fraction measured in positions $\mathrm{A}$ and $\mathrm{C}$, i.e. in the middle of the thickness and on the surface of a cyclically strained sheet respectively, is plotted vs. number of cycles. It is clear that in the early stage of cycling much higher content of $\alpha^{\prime}$-martensite in all three microstructural states is found in the middle of sheet thickness. This indicates the presence of some form of magnetic anisotropy across the sheet thickness. With continuing cycling, however, the relative 

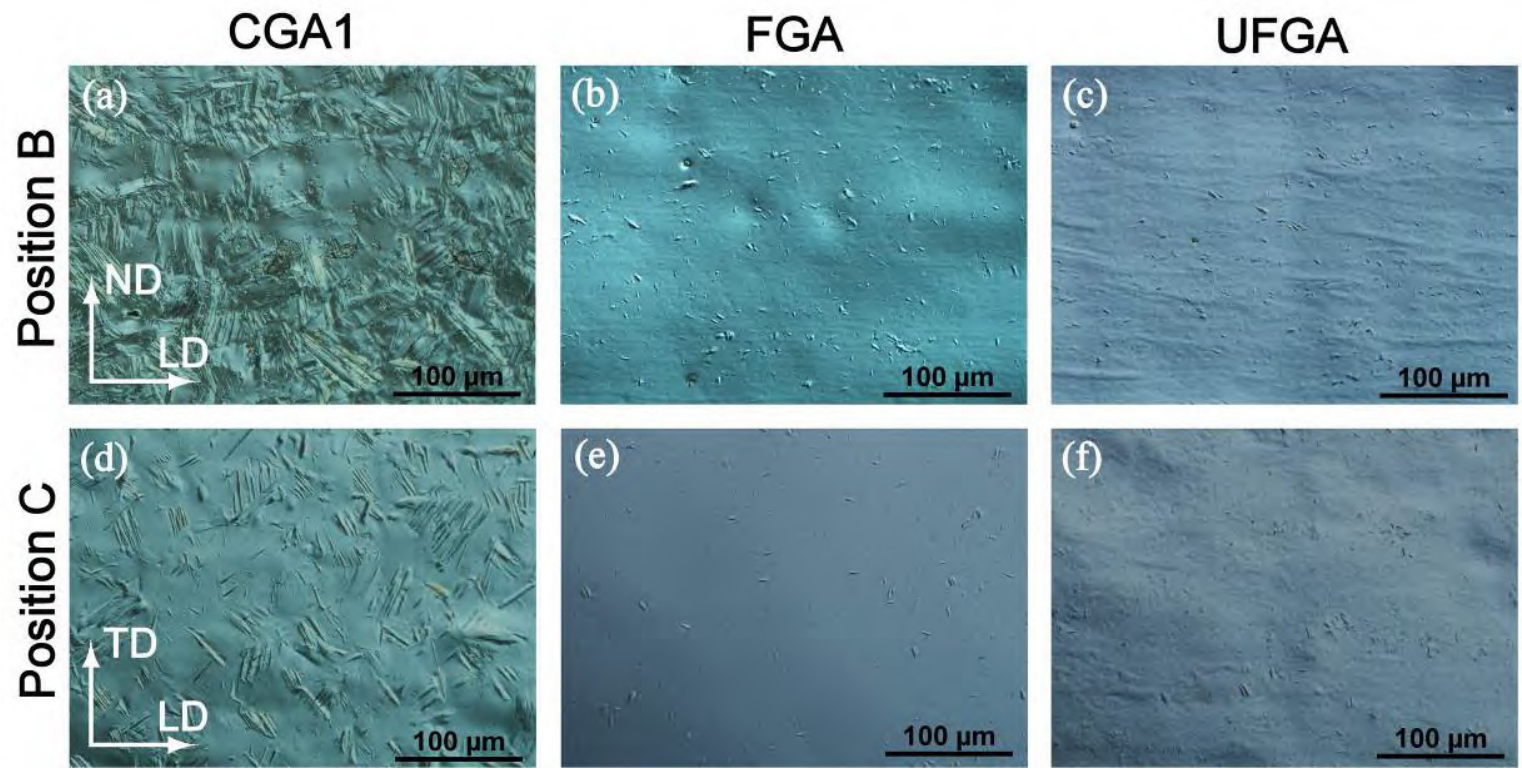

Fig. 6. Surface topography outside the central part of sheet thickness (position B) and on the sheet surface (position C) of 301LN steel with different grain sizes fatigued with $\varepsilon_{\mathrm{at}}=0.5 \%$ to the very early stage of fatigue life (OM, polarized light). Stress axis is horizontal in all micrographs (c.f. Fig. 1b).

differences in $\alpha^{\prime}$-martensite content decrease gradually up to the value of $5 \%$ documented for FGA and CGA1 microstructures. Only UFGA microstructure still shows a higher difference of $15 \%$ at later stage of cycling.

\subsubsection{Post mortem characterization of DIM in the very early stage of cyclic straining}

To bring more insight into the specific features revealed for $301 \mathrm{LN}$ steel with various grain sizes in the early stage of cycling, namely the characteristic changes of hysteresis loop shapes and the presence of magnetic anisotropy across the sheet thickness, individual specimens were cyclically strained to the very early stage of fatigue life. Then the surface at different positions within the gauge part of specimens (both on the sheet surface and across the sheet thickness), carefully electrolytically polished prior fatigue tests, was documented by optical microscopy in polarized light and EBSD technique.

An example of the surface observations using polarized light - an extremely sensitive technique for visualization even of very fine slip features - for all microstructural states of $301 \mathrm{LN}$ steel is presented in Figs. 5 and 6. Fig. 5 shows the surface topography across the whole specimen thickness and the details of surface topography in the places denoted $\mathrm{A}, \mathrm{B}$ and $\mathrm{C}$, the position of which is schematically indicated in Fig. 1b, are shown in Figs. 5 and 6.

Fig. 5a witness that the density of slip markings generated in coarse-grained steel in the plane LD-ND after 150 cycles is relatively high. Even though it can locally fluctuate across the sheet thickness (see some featureless areas or even a band in the middle of sheet thickness in Figs. 5a and 6a), at macroscopic scale it remains approximately constant - cf. Figs. 5a and 6a. Contrary to this situation much lower density of slip

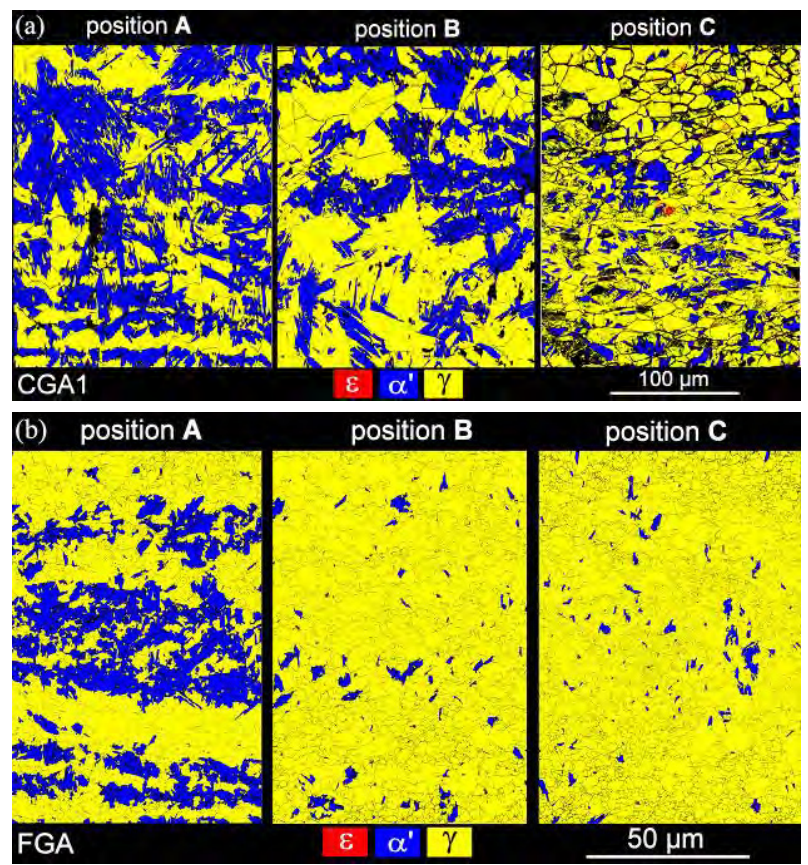

Fig. 7. Microstructure of coarse-grained (a) and fine-grained (b) $301 \mathrm{LN}$ steel fatigued with $\varepsilon_{\text {at }}=0.5 \%$ to the very early stage of fatigue life as revealed by EBSD at different positions indicated in Fig. 1b. Stress axis is horizontal in all micrographs.

markings has been revealed on the sheet surface, i.e. in the position $\mathrm{C}$ as apparent from Fig. $6 \mathrm{~d}$.

The surface observations of grain-refined structures yield considerably different picture on the distribution of slip markings within the volume of cyclically strained steels. The bands of high density of fine slip markings, much finer in comparison with those detected in CGA1 steel, separated by featureless areas were detected after 100 cycles in the central part of the sheet thickness (see details corresponding position A in the insets in Figs. 5b 
Table 2. Results of quantitative assessment of microstructure of $301 \mathrm{LN}$ steel (FGA and CGA1 states) by EBSD and Feritscope at the very early stage of cyclic straining.

\begin{tabular}{|c|c|c|c|c|c|c|}
\hline \multirow{2}{*}{$\begin{array}{l}\text { Microstructural } \\
\text { state and fatigue } \\
\text { conditions }\end{array}$} & \multirow{2}{*}{$\begin{array}{l}\text { Position of EBSD } \\
\text { or Feritscope } \\
\text { measurement }\end{array}$} & \multicolumn{4}{|c|}{ Phase fraction (EBSD) } & \multirow{2}{*}{$\begin{array}{l}\text { Vol. fraction of } \alpha^{\prime}- \\
\text { martensite [\%] } \\
\text { (Feritscope) }\end{array}$} \\
\hline & & $\begin{array}{l}\varepsilon \text { (h.c.p.) } \\
{[\%]}\end{array}$ & $\begin{array}{l}\gamma \text { (f.c.c.) } \\
{[\%]}\end{array}$ & $\begin{array}{l}\alpha^{\prime} \text { (b.c.c.) } \\
{[\%]}\end{array}$ & $\begin{array}{l}\text { Zero solution } \\
{[\%]}\end{array}$ & \\
\hline \multirow{3}{*}{$\begin{array}{l}\text { FGA (\#PI 4) } \\
\varepsilon_{\text {at }}=0.6 \% \\
\mathrm{~N}=100 \text { cycles }\end{array}$} & $\mathrm{A}$ & 0.47 & 60.25 & 29.31 & 9.97 & $3.37 \pm 0.49$ \\
\hline & $\mathrm{B}$ & 0.38 & 90.48 & 3.40 & 5.74 & not measured \\
\hline & $\mathrm{C}$ & 0.21 & 90.90 & 2.72 & 6.18 & $1.98 \pm 0.29$ \\
\hline \multirow{3}{*}{$\begin{array}{l}\text { CGA1 (\#PI 1) } \\
\varepsilon_{\mathrm{at}}=0.5 \% \\
\mathrm{~N}=150 \text { cycles }\end{array}$} & $\mathrm{A}$ & 0.53 & 42.48 & 44.18 & 12.82 & $19.61 \pm 0.36$ \\
\hline & $\mathrm{B}$ & 0.70 & 56.72 & 29.29 & 13.30 & not measured \\
\hline & $\mathrm{C}$ & 0.97 & 60.39 & 12.32 & 26.33 & $12.01 \pm 0.41$ \\
\hline
\end{tabular}

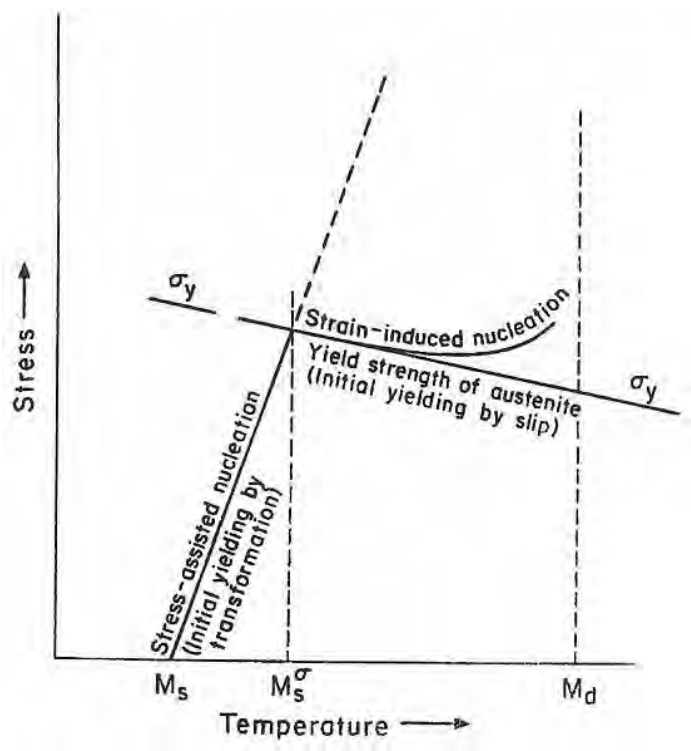

Fig. 8. Schematic representation of interrelationships between stress-assisted and strain-induced nucleation of $\alpha^{\prime}$-martensite in metastable austenitic alloys (after [23]).

and 5c). The thickness of individual bands can fluctuate along the gauge length. Even though some individual bands are discontinuous along the R.D., macroscopically the area of individual band occurrence is running along the whole gauge part of specimen; its thickness is around $500 \mu \mathrm{m}$ for both FGA and UFGA structures. Outside the central part of sheet thickness (see microstructure in position B in Figs. $6 \mathrm{~b}$ and $6 \mathrm{c}$ ) the density of slip markings, approximately randomly distributed in the material, is considerably lower. The sheet surface is nearly featureless for both grain-refined structures (see Figs. 6e and $6 \mathrm{f}$ showing microstructure in the position $\mathrm{C}$ in FGA and UFGA steel, respectively).

The EBSD mapping with a step size of $85 \mathrm{~nm}$ in the above mentioned areas $\mathrm{A}, \mathrm{B}$ and $\mathrm{C}$ was performed for all 301LN steel structures. Figs. $7 \mathrm{a}$ and $7 \mathrm{~b}$ show the result obtained for CGA1 and FGA structures. Quantitative data on the EBSD phase analysis are together with the results of Feritscope measurements listed in Table 2.

Comparing EBSD phase maps with Figs. 5 and 6 a very good agreement can be seen between two different microscopic techniques. Nearly compact band-like areas of high density of $\alpha^{\prime}$-martensite are apparent in the central parts of sheet thickness of both CGA1 and FGA steel (see position A in Fig. 7a and 7b). Much lower density of $\alpha^{\prime}$-martensite distributed relatively randomly in the material is typical for the areas outside the central part of the sheet thickness (position B) and as well as for the sheet surface (position C) - see Fig. 7b. Situation in coarse-grained material seems to be more complex, cf. phase maps in Fig. 7a. Whereas at the position B the character of $\alpha^{\prime}$-martensite remains practically similar to that in the position A with lower $\alpha^{\prime}$-martensite density, numerous black dots (i.e. not resolved) in the phase map of sheet surface (place $\mathrm{C}$ ) and corresponding presumably to $\alpha^{\prime}$-martensite indicate clearly a possible change in deformation mechanisms in the areas of higher stability of austenite.

Comparison of quantitative data on the $\alpha^{\prime}$-martensite content assessed at different positions of fatigued 301LN steels by the EBSD technique and Feritscope (see Table 2) shows that both methods reflect an inhomogeneous $\alpha^{\prime}$-martensite distribution across the sheet thickness in the very early stage of cycling. The local EBSD analysis indicates that the differences in $\alpha^{\prime}$-martensite fraction in the central parts of sheet thickness and the remaining parts of the sheet may be even much higher than those found by Feritscope (cf. quantitative data in the position $\mathrm{A}$ and positions $\mathrm{B}$ and $\mathrm{C}$ for both $301 \mathrm{LN}$ steel in Table 2).

\section{Discussion}

The experimental study on the destabilization of the initially fully austenitic structure during cyclic straining of $301 \mathrm{LN}$ steel grain-refined to three different grain sizes of $13 \mu \mathrm{m}$ (CGA1), $1.4 \mu \mathrm{m}$ (FGA) and $0.6 \mu \mathrm{m}$ (UFGA) brought several very important results.

Both in situ Feritscope measurements during cyclic straining and post mortem EBSD analysis showed that the $\alpha^{\prime}$-martensite is not distributed homogeneously across the sheet thickness. The most metastable part in all grain-refined structures was always the central part of the sheet thickness. This inhomogeneity in the $\alpha^{\prime}$ martensite distribution resulting in a magnetic anisotropy is highest in the very early stage of fatigue tests and with continuing cycling gradually decreases (see Fig. 4b). This finding agrees with our previous results on cyclically strained grain-refined $301 \mathrm{LN}$ steels $[10,16$, $20,21]$ and it can be rationally reconciled with our recent studies on the stability of various product forms of wrought AISI 304-type [20, 22] and 316-type [20] austenitic stainless steels. Both studies demonstrated convincingly that that these $\mathrm{Cr}-\mathrm{Ni}$ austenitic steels are never fully chemically homogeneous and furthermore 
due to the specific solidification behaviour and contemporary continuous casting practice the most metastable area of any wrought full-cross-section semiproduct is always its central part. The local chemical analysis proved the presence of characteristic local variations in chemistry (and thus in the austenite stability) in the form of chemical banding and showed the validity of the above statements also in case of 301LN steel [16].

To understand the characteristic changes of hysteresis loop shape and the presence of cyclic softening at the early stages of cyclic straining of 301LN steel with FGA and UFGA structure the specific nature of $\alpha^{\prime}$-martensite formation has to be taken into account.

Olson and Cohen in their concept of deformation induced martensitic nucleation distinguish between two mechanisms (see Fig. 8) [23]), namely the stress-assisted nucleation occurring at temperatures between $\mathrm{M}_{\mathrm{S}}$ and $\mathrm{M}_{\mathrm{S}}^{\sigma}$, and the strain-induced nucleation above $\mathrm{M}_{\mathrm{s}}^{\sigma}$. The character of $\alpha^{\prime}$-martensite formation during stressassisted transformation is similar to that at usual spontaneous transformation below $\mathrm{M}_{\mathrm{s}}$ at which the nucleation of $\alpha^{\prime}$-martensite plates at the specimen surface is accompanied by the characteristic surface topography $[24,25]$ and by a rapid local volume expansion of $2.57 \%$ [26]. These surface features are clearly apparent from the optical micrographs taken in polarized light for all microstructural states in Figs. 5 and 6.

In the early stage of cycling of FGA and UFGA structures the stress-assisted nucleation of $\alpha^{\prime}$-martensite is concentrated into thin bands the occurrence of which is restricted primarily only to the $500 \mu \mathrm{m}$ thick central part of the sheet (see Figs. 5b and 5c) while the remaining parts of the sheet which are affected much less by the $\alpha^{\prime}$-martensite formation (see Figs. $6 \mathrm{~b}, \mathrm{c}$ and $6 \mathrm{e}, \mathrm{f})$. Due to the rapid volume expansion accompanying martensite formation the central part of fatigued sheet is thus in the state of internal compression stress and internal tensile stress is present in the remaining, much larger part of the material within the specimen gauge part. In the total strain controlled fatigue tests this situation will lead to the gradual development of small tensile mean stress and small increase of the hysteresis loop width, i.e. cyclic softening. As soon as the formation of stress-assisted $\alpha^{\prime}$-martensite bands ceases and a sufficient amount of $\alpha^{\prime}$-martensite will be generated also outside the most metastable central part of the sheet, the internal compression stress develops in the whole volume of the fatigued material and this will result in the start of intensive cyclic hardening. As is apparent from Fig. $2 \mathrm{a}$ and $2 \mathrm{~b}$ the above described processes require in FGA and UFGA steels, cyclically strained with total strain amplitude of $0.6 \%$, typically $100-150$ cycles.

Contrary to the described behaviour, the situation in destabilization in coarse-grained CGA1 steel is much simpler. Due to the fact that the stress-assisted $\alpha^{\prime}$ martensite (presumably accompanied also by the straininduced $\alpha^{\prime}$-martensite) is distributed more uniformly in
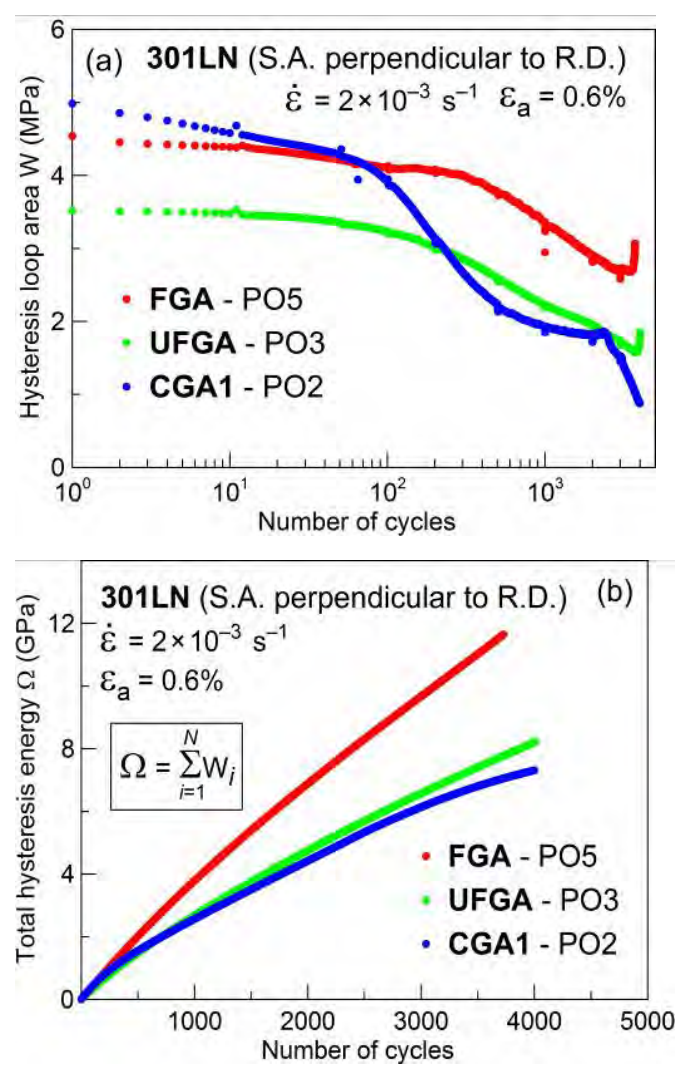

Fig. 9. Mean dissipated energy in a cycle (a) and total hysteresis energy (b) versus number of cycles in $301 \mathrm{LN}$ steel with different grain sizes.

the whole volume of material, the permanent internal compression stress will be present within the specimen gauge length. It results in the gradual development of the compression mean stress and permanent cyclic hardening as apparent from Fig. 2.

The presence of hysteresis loop constriction in the early stage of cycling of FGA and UFGA steels can be rationally explained by the nature of stress-assisted nucleation of $\alpha^{\prime}$-martensite in the form of thin bands. Due to this specific localized mode of $\alpha^{\prime}$-martensite formation accompanied by rapid volume expansion an extra-strain arises. In the total strain controlled test this event results in the drop of stress both in tensile and compression part of the hysteresis loop (at stress level well below macroscopic yield stress) and hysteresis loops thus become visually constricted as apparent from Fig. 3.

In order to explain much slower rate of $\alpha^{\prime}$-martensite formation in FGA structure fatigued with the frequency of $1 \mathrm{~Hz}$ contrary to the strain rate of $2 \times 10^{-3} \mathrm{~s}^{-1}$ adopted in the present work the actual temperature of the specimen gauge part during cyclic straining should be taken into account. Since the related temperature measurements are still in progress only some energetic considerations will be discussed here.

Fig. 9 shows both the development of hysteresis loop area and total hysteresis energy for all microstructures cycled with low strain rate of $2 \times 10^{-3} \mathrm{~s}^{-1}$ whose stressstrain response is shown in Fig. 2. The hysteresis loop area decreases gradually during the strain hardening in all structures, nevertheless as can be seen from Fig $2 \mathrm{a}$ 
the FGA structure due to higher cyclic plasticity (see also Fig. 3) has the highest hysteresis loop area during cycling. Since the fatigue process has a cumulative character much more important dependence is that shown in Fig. 9b. As can be seen from this dependence the total dissipated energy in FGA structure after several hundreds of cycles start to systematically deviate from those evaluated for CGA1 and UFGA structures. Since the great majority of hysteresis energy dissipates in heat [27] and taking into account a generally low thermal conductivity and especially low thermal diffusivity of austenitic stainless steels [28] it is feasible to expect a small but continuous increase of temperature due to adiabatic heating during cycling with the frequency of $1 \mathrm{~Hz}$ used by Järvenpää et al. [10]. Since the characteristic temperature $\mathrm{M}_{\mathrm{d} 30}$ is $23{ }^{\circ} \mathrm{C}$ for the present AISI 301LN steel [10], it is clear that even a small increment in temperature during fatigue tests can have an important impact on the stability of the structure and thus on the stress-strain response. However, as indicated recent results by Pegues et al. for AISI 304L austenitic steel with normal grain size [29], the effect of higher strain rates can have a beneficial effect on fatigue life in total strain controlled fatigue tests. Such behaviour should be, however, in the case grain-refined austenitic structures validated experimentally.

The support of the present work by the grant No. 13-32665S from GAČR and by the research project RVO 68081723 is gratefully acknowledged.

\section{References}

1. L.P. Karjalainen, T. Taulavuoiri, M. Sellman, A. Kyröläinen, Steel Res. Int. 79, 404 (2008)

2. R.D.K. Misra, S. Nayak, P.K.C. Venkatasurya, V. Ramuni, M.C. Somani, L.P. Karjalainen, Metall. Mater. Trans. A 41, 2162 (2010)

3. R.D.K. Misra, V.S.A. Challa, P.K.C. Venkatsurya, Y.F. Shen, M.C. Somani, L.P. Karjalainen, Acta Mater. 84, 339 (2015)

4. B. Ravi Kumar, S. Sharma, B.P. Kashyap, N. Prabhu, Mater. Des. 68, 63 (2015)

5. M. Shirdel, H. Mirzadeh, M.H. Parsa, Mater. Charact. 103, 150 (2015)

6. P. Behjati, A. Kermanpur, L.P. Karjalainen, A. Järvenpää, M. Jaskari, H. Samaei Baghbadorani, A. Najafizadeh, A. Hamada, Mater. Sci. Eng. A 650 119 (2016)

7. C. Celada-Casero, B.M. Huang, M.M. Aranda, J.-R. Yang, D. San Martin, Mater. Charact. 118, 129 (2016)

8. D.M. Xu, G.Q. Li, X.L. Wan, R.L. Xiong, G. Xu, K.M. Wu, M.C. Somani, R.D.K. Misra, Mater. Sci. Eng. A 688, 407 (2017)

9. A. Järvenpää, M. Jaskari, J. Man, L.P. Karjalainen, Mater. Charact. 127, 12 (2017)

10. A. Järvenpää, M. Jaskari, J. Man, L.P. Karjalainen, Mater. Sci. Eng. A 703, 280 (2017)
11. A. Järvenpää, M. Jaskari, L.P. Karjalainen, Metals 8, 109 (2018)

12. C. Lei, X. Li, X. Deng, Z. Wang, G. Wang, Mater. Sci. Eng. A 709, 72 (2018)

13. J.-B. Vogt, A. Poulon, S. Brochet, J.-C. Glez, J.-D. Mithieux, in Sixth Int. Conf. on Low Cycle Fatigue (LCF6), P.D. Portella, T. Beck and M. Okazaki, eds., pp. 97-102 (DVM e.V., Berlin, 2008)

14. A. Poulon, S. Brochet, J.-C. Glez, J.-D. Mithieux, J.B. Vogt, Adv. Eng. Mater. 12, 1041 (2010)

15. A. Chlupová, J. Man, I. Kuběna, J. Polák, L.P. Karjalainen, Proc. Eng. 74, 147 (2014)

16. J. Man, A. Chlupová, I. Kuběna, T. Kruml, O. Man, A. Järvenpää, L.P. Karjalainen, J. Polák, in Eighth Int. Conf. on Low Cycle Fatigue (LCF8), T. Beck and E. Charkaluk, eds., pp. 205-210 (DVM e.V., Berlin, 2017)

17. M. Droste, C. Ullrich, M. Motylenko, M. Fleischer, A. Weidner, J. Freudenberger, D. Rafaja, H. Biermann, Int. J Fatigue 106, 143 (2018)

18. J. Talonen, P. Aspegren, H. Hänninen, Mater. Sci. Technol. 20, 1506 (2004)

19. A. Järvenpää, M. Jaskari, L.P. Karjalainen, unpublished results (2017)

20. J. Man, I. Kuběna, M. Smaga, O. Man, A. Järvenpää, A. Weidner, Z. Chlup, J. Polák, Proc. Struct. Integr. 2, 2299 (2016)

21. J. Man, A. Chlupová, I. Kuběna, M. Valtr, A. Järvenpää, T. Kruml, L.P. Karjalainen, J. Polák, Acta Mater. (to be published)

22. J. Man, M. Smaga, I. Kuběna, D. Eifler, J. Polák, Eng. Fract. Mech. 185, 139 (2017)

23. G.B. Olson, M. Cohen, J. Less-Common Metals 28, 107 (1972)

24. D.A. Porter, K.E. Easterling, Phase transformations in metals and alloys (Van Nostrand Reinhold (UK), 1986)

25. G.B. Olson, W.S. Owen, eds., Martensite: A tribute to Morris Cohen (ASM International, 1992)

26. P. Marshall, Austenitic stainless steels: microstructure and mechanical properties (Elsevier Applied Science Publishers, London and New York, 1984)

27. M. Smaga, F. Walther, D. Eifler, Mater. Sci. Eng. A 483-484, 394 (2008)

28. L. Bodelot, L. Sabatier, E. Charkaluk, P. Dufrénoy, Mater. Sci. Eng. A 501, 52 (2009)

29. J.W. Pegues, S. Shao, N. Shamsaei, J.A. Schneider, R.D. Moser, Fatigue Fract. Engng Mater. Struct. 40, 2080 (2017) 